in short, one cycle is in this respect almost as good or as bad as another.

Now, if in any series of quantitics, such as the rainfall observations at Madras, there be a law of periodicity, each observed quantity may be supposed to be compounded of a periodical and a non-periodical element. If we take the sum of a large number of cycles, each of which coincides with the cycle of periodicity, the non-periodical elements will tend to be eliminated, and the means for the successive years of the cycle will indicate the periodical elements for the successive intervals. At the same time the differences of these means from the several original quantities from which they were obtained will be the several nonperiodical elements.

In proportion as the periodical elements are small or large in relation to the corresponding non-periodical elements, so the differences (obtained as above) will be inversely less or more different from the differences between the individual observations and the mean of the whole of them ; and if there be no periodicity, the two sets of differences would, in a sufficiently long series, be identical.

Hence it may be inferred that when the differences (taken as before) closely approximate in miagnitude to the mean (lifference of the original observations from the arithmetical mean of all of them, the periodical elements in those observations must be correspondingly small; and this applies manifestly to the eleven year-cycle and to the whole of the arbitrary cycles for which the differences were calculated.

Further to test the reality of the periodicity, the author re. arranged the series of sixty-four years' observations, in a purely arbitrary manner, in cycles of eleven years, by drawing the actual observations at random one after another, and setting them down in succession ill the whole were exhausted. From three arhitrary cycles thus prepared, the differences averaged $10 \%$, II'2, and II.6-results which again indicate that the actual sequence of the observed quantities of rain has no material effect on the mean differences, or any such tendency to a diminution in their numerical value, which is the necessary accorapaniment of a true periodical element.

Moreover, the mere circumstance of any series of cyclical means showing a single maximum and single ninimurn gives no real indication of such a result being a truly periodical feature. It is obviously to argue in a circle, first to assume a cycle on which to work, which shall give a single maximum and minimum, and then to infer that there is true periodicity because of the single maximum and minimum. The test of the periodicity is in truth to be sought altogether outside of the particular values of the successive elements of the cyclical means.

It is manifest that a complication of periodical elements may so mask one another as to prevent positive results being obtained by the examination of the means and differences in the case before us. But the whole scope of the present argument is negative, and it leads to the conclusion that there is no proof of greater tendency to periodicity in the eleven-year means than in the original isolated observations.

As the sun spot period is not exactly a cycle of eleven years, the author examined the results obtained by a comparison of the observations corresponding to the known periods of maximum and minimum sun-spots, without reference to any special length of cycle. These results he also considered to be negative.

A further test of the character of the conclusions was sought from the rainfall observations at Bombay and Calcutta, which have been made for the greater part of the period over which those at Madras extend. It is hardly conceivable that there should be a coincidence with the sun-spot period, such as is supposed to have been found at Madras, based on any physical cause, which should not in some way be discernible in the rainfall at Bombay and Calcutta.

The results thus got are also held to be entirely negative, and to indicate no concordance among the means of the several years of the cycle at the different places. The Bombay and Calcutta observations, treated as those of Madras were, to ascertain the deviations of individual observations from the successive means of the cycle, give quite similar results.

Although the special object of the communication was to deal with the alleged correspondence between the Madras rainfall and the sun-spot periods, the author had also turned his attention to Mr. Meldrum's speculations of a similar character, and had tested some of them in the manner explained.

Among these were the Greenwich observations for fifty-five years, which will be found at p. 307 of vol. xxi. of the Proceed. ings of the Royal Society, and the results got from them were quite analogous to that obtained from the Indian observations.

Further, to illustrate the argument on which the paper was based, the case was considered, in which a well-ascertained periodicity exists, as that of the diurnal barometric oscillation. The figures used were taken at random from an old Madras register, the intervals being made two-hourly, and the entries and the differences of the observed barometric heights from the daily means in thousandths of an inch, $s^{\prime}$ ) as to reduce the calculations.

The figures being merely illustrative, the circurxstance of their not exactly representing any physical phenomenon $n_{s i}$ was a matter of no significance.

The treatmext of these figures led to results very different from those rot from the rainfall observations. The mean difference of all the supposed observations from the mean of all of then being thirty, the mean of the differerices between the two-hourly means and the original figures was reduced to seven, indicating the distinct presence of a periodicity.

Re-arranging the figures in an arbitrary cycle of ten periods instead of twelve, the mean of the differences which before was seven was increased to thirty, showing that with the total destruction of the periodicity the mean difference of the two-hourly means and the original figures was the same as the menn difference with the arithmetical mean of all of them.

In conclusion, the author specially explained that he did not call in question the possible or actual occurrence of terrestrial phenomena corresponding to the sun-spot period, but cnly desired to point out that in the case of the rainfall observations under review the eviderice was not sufficient to establish either any periodicity or such a correspondence.

In some remarks made subsequently the author pointed out how the comparison of the successive combinalion of the observations, beginning with one cycle and then combining two, and so on, till the whole were united, supplied another way of treating the fig rres which showed that the successive means of the differences between the mean rainfall for the combined cycles and the mean for the several years of the cycle when combued, followed the law that would hold good if there were no appreciable periodicity, that is to say, that this mean should gradialiy cimiwish in a ratio inverse to the square roo: of the number of cycles combined.

\section{UNIVERSITY AND EDUCATIONAT} INTELLIGENCE

Cambridge.-Prof. Humphry has been appointed to represent the University at the 4ooth anniversary of the University of Upsala in September next.

Prof. Adamis' report to the observatory syndicate for the year from May, 1876 , to May, 1877 , does not contain anything of unusual interest. The year has been exceptionally favourable for astronomical observations, and 3,6r8 observations were made with the Transit circle. All the publications of the observatory are well forward, and the general work has been carried on smoothly and efficiently.

The following awards have been made for proficiency in natural science at St. John's College :-To F. T. S. Houghton, a foundation scholarship, the Wright's Prize, and augmentation of exhibition to 1ool. for the past year. To Marr, Slater, F. J. Allen, Stewart, augmentations of exhibitions.

LoNDoN.- A public meeting in support of the London School of Medicine for Women was held the other day at St. Gtorge's Hall, the especial object being to raise $5,000 l$, with a view of enabling the Executive Council to carry out an arrangement with the authorities of the Royal Free Hospital, under which students from the school were to receive clinical instruction. Mr. CowperTemple, M.P., Mrs. Garrett-Anderson, and Mrs. Westlake were amongst the speakers. 2,600l. have already been subscribed.

The Senate of the London University have decided by a majority of five not to postpone giving medical degrees to women till all the other faculties were open to them.

MANCHESTER.--On Friday last the scholarships and prizes gained during the session by students in the Faculties of Arts, Science, and Law were distributed at the Owens College. The Dalton Senior Mathematical Scholarship was gained by J. P. Whitney; the Dalton Junior Mathematical Scholarship by J. D. Pennington; the Daiton Chemical Scholarship by J. K. Crow; the Platt Physiological Scholarship by L. Larmuth. Mr. Crow presented a research upon the "Hypovanadous Compounds," 
and Mr. Larmuth a research upon the "Physiological Action of certain Vanadium Compounds." The number of students in the various departments of the College during the session just closed has been-Arts, Science, and Law, 415; Medicine, 175 ; Evening Classes, 900; making a total-allowing for double entries-of 1,450 , being an increase of seventy on the number registered during the session of $1875^{-76}$.

LEEDS.-On Saturday the prizes and certificates awarded to the students at the termination of the third session of the Yorkshire College of Science were distributed by Lord Frederick C. Cavendish, the President of the College. Thoroughly gratifying reports of progress were made by all the professors. Not only has a site been obtained for the erection of permanent buildings, but an architect has been appointed to prepare plans and superintend the erection of the buildings. The first step has been taken to provide what we have all along advocated, a complete curriculum in literature as well as in science, by the appointment of Mr. Marshall as classical professor, and it is hoped that in a very short time a professor of modern literature will also be added to the staff. Liberal contributions have already been made towards the great expenses required to start the institution, and the University Extension Committee have handed over the whole of the funds of which they had been made administrators in connection with Leeds. Still to attain anything like efficiency the sum already obtained must be doubled. It is the people of Yorkshire who will mainly benefit by this new institution, and we hope it will not be difficult to convince them that it is both their interest and their duty to provicle the greater portion of the funds required.

Durham. - At a recent Convocation the following degrees and licences were conferred in connection with the University :B.Sc. : John Thomas Dunn, Mather Scholar. Associates in Physical Science: Edwin Cooke, John Richard Hutchinson Williamson.

PARIS. - The reconstruction of Charlemagne College, one of the most celebrated national colleges in Paris, has just been finished. The fitting-up of the buildings has begun, and they will be ready by October next. This college was established after the Revolution in the Hotel d'Anvilla, rie St. Antoine, which had been purchased from Anne de Montmorency by the Carcinal of Bourbon, and bequeathed by him to the Jesuits, then in hostility with the University.

A large number of houses having been pulled down in the Quartier Latin to make room for the Boulevard St. Germain, the works for the enlargement of the School of Medicine have been begun, and will be completed before the Exhibition. The expense will be $2,838,000 \mathrm{fr}$.

\section{NOTES}

Tire varied and cultured tastes of the Emperor of Brazil are unusual even among private individuals, and probably without a parallel among his own limited class; his activity and eagerness for knowledge are astonishing. While in Paris, as we stated at the time, he was present at almost every scientific meeting of any importance, and in London this interest in science manifests itself quite as strongly. He has attended every meeting of the Royal Society since his arrival, was present at Mr. A. R. Wallace's lecture, carefully inspected the Science School at South Kensington, called the other day on Mr. Crookes, visited Dr. Siemens on Tuesday and Mr. Spottiswoode on Wednesday, and indeed has conversed with almost every man of science in London who has been doing any original work during the past few years. These visits are not mere formalities, for the Iimperor is not satisfied until he masters whatever new research is submitted to him. On Tuesday he was made an honorary member of the Anthropological Institute and of the Royal Historical Society. Were the Emperor to stay here for some time we believe his presence would have a distinct influence on the public recognition of science; and if there were any one in this country in a similar station who took an equally real interest in science, we believe it would be all the better.

UNDER the auspices of the Sanitary Institute,' Dr. Richardson, F.R.S., will deliver a lecture at the Royal -Institution, Albe- marle Street, on Thursday next, at 4 P.M., "On the Future of Sanitary Science in relation to Political, Medical, and Social Progress." We hope to give a verbatim report of this lecture in next week's number.

THE last meeting of the Royal Society previous to the recess was held last Thursday.

WE regret to see that Poggendorff's name has been entirely suppressed in the title-page of the new volume of the Annalen. The journal now edited by Borchardt still bears Crelle's name, and our Philosophical Magazine still keeps the names of Tilloch, Nicholson, and Thomson on its title-page. A similar allusion to the man who has made the Annalen what they are, would have been a better tribute to his memory than the short account of his life which closes what we must now call the last volume of Poggendorff's Annalen.

THE twenty-sixth meeting of the American Association for the Advancement of Science will be held at Nashville, Tennessee, commencing August 29, 1877 . The president at this meeting will be Prof. Simon Newcomb ; the permanent secretary is Prof. F. W. Putnam.

THE Geologists' Association have arranged for an excursion into Derbyshire on Monday, July 23 and five following days, under the direction of the Kev. J. M. Mello, Prof.Boyd Dawkins, and $\mathrm{Mr}$. Rooke Pennington.

THE Select Committee to which the Ancient Monuments' Bill was referred met on Monday, when Sir John Lubbock was chosen chairman. The Committee meets again on Monday next, when evidence will be taken.

At the meeting of the Royal Geographical Society on Morday, the last of the three lectures on scientific geography arranged for this session was given by Mr. A. R. Wailace, "On this Comparative Antiquity of the Continents." The object of the lecture was to establish the comparative antiquity of continents by an examination of the living and extinct animals found in each, and the lecturer came to the general conclusion that the main divisions of the earth had been nearly the same from the earliest period. The Emperor of Brazil was present during the lecture.

IN our report of the Anniversary Meeting of the Geographical Society it was stated that the Society contemplated organising an African Exploration Fund. The Society, it is known, has taken no share in the International African Association founded by the King of the Belgians; while doing everything to forward the views of that association, it seems to be of opinion that England ought to carry out African exploration independently. The Prince of Wales has become patron of the African Fund, and a special committee has been appointed, with the president of the society as chairman, the society having given a special donation of $500 l$. A map accompanying the programme of the scheme shows how large an area has been explored by British travellers, and several routes in Eastern Africa are suggested for exploration or careful examination. A comparison has been made of the length of each journey in Africa in a few recent instances, with the cost of making it. It appears that the total expense of despatching a well-equipped exploratory expedition from England may be roughly reckoned at the rate of $1 \%$. IOs. for each geographical mile of country travelled over in Africa, supposing the expedition to return to the place whence it set out. In through journeys the rate is in many cases nearly twice as great. The aggregate length of the seven specified routes is about 7,700 geographical miles; consequently, the total cost of the proposed explorations, at the atove rate; would amount to about $I I, 550 l$. No doubt many besides fellows of the society will be willing to help forward this new scheme. In connection with this we may. here state 